\title{
Editorial
}

\section{Dangerous Liaisons. Potentialities and Risks Deriving from the Interaction between Artificial Intelligence and Preventive Justice}

One of the crucial challenges of social and economic development in current times concerns how States will be able take advantage and make an appropriate use of AI and ML systems. ${ }^{1}$ The EU, inevitably well aware of this, has embarked on a digital agenda that intends to explore all possible employments of AI while respecting the rights of citizens, as the recent establishment by the European Parliament of the special committee on Artificial intelligence in a Digital Age (AIDA) confirms. ${ }^{2}$ The ability of AI systems to interact with the most diverse areas of human life has also had an impact on the thinking of legal experts, making

1 According to Contissa and Lasagni, an Artificial Intelligence system "Rather than carrying out evaluations and assessments on the basis of an algorithm containing a set of rules predefined by the programmer, the system builds its own model of the domain, applying a learning algorithm to analysis of the training data. Using this model, the system generates classifications, evaluations, and predictions on new cases submitted to it. Updating and expanding the dataset automatically improves the model and the system's predictive capabilities" (G. Contissa and G. Lasagni, 'When it is (also) Algorithms and AI that decide on Criminal Matters: In Search of an Effective Remedy', European Journal of Crime, Criminal Law and Criminal Justice, 2020, 280-304, p. 281). As Hildebrandt affirms with regard to Machine Learning systems (quoting Mitchell) "A computer program is said to learn from experience E with respect to some class of tasks $\mathrm{T}$ and performance measure $\mathrm{P}$, if its performance at task $\mathrm{T}$, as measured by $\mathrm{P}$, improves with experience" (M. Hildebrandt, Smart Technologies and the End(s) of Law, Edward Elgar, 2015, p. 35; T. M. Mitchell, Machine Learning, Burr Ridge, McGraw Hill, 1997, p. 2).

2 As it is reported in the AIDA webpage (https://multimedia.europarl.europa.eu/it/aida-specialcommittee-on-artificial-intelligence-in-digital-age_16506_pk), "The special committee AIDA 
increasing inroads into lawyers' reflection. In fact, the possibility to use AI and ML systems to deal with the most diverse fields of the law constitutes a matter of study and engagement for lawyers, both practitioners and academics, no matter what their cultural background is. It can be perhaps affirmed that the theoretical study on the impact of AI on legal issues, at least with regard to certain areas of the law, started ahead of the time when AI system will have on them an effective impact. ${ }^{3}$

This proactive attitude by lawyers and legal scholars toward the topic is due to various reasons. For example, law firms are aware that the quality and type of work in the area of legal advice and in litigation will considerably change thanks to the development of technology and the employment of AI systems. ${ }^{4}$ Probably, however, the most important reason why legal theoretical reflection started early is due to a common feature that binds together AI and the law, both sharing the capacity to be pervasive and omnipresent. With regard to the former, as it brilliantly was observed, we live surrounded by information technology - creating a wholly new a proper environment, the infosphere ${ }^{5}$ - and our lives are conditioned, for better or worse, by digital devices, that can be progressively considered artificial extensions of our limbs. ${ }^{6}$ We are continuously onlife, as it has been affirmed, and AI systems, thanks to the Internet of Things, is constantly present in our lives. ${ }^{7}$ The same happens with the law, that interferes with the different facets the whole life of human beings (even when they think to have left the law outside their businesses): while the acknowledgment of living in an infosphere

on artificial intelligence will study the impact and challenges of rolling out AI, and propose a roadmap with objectives for the EU in the field of AI and the steps that need to be taken to achieve them. Its mandate is to analyse the future impact of artificial intelligence in the digital age on the EU economy, in particular on skills, employment, fintech, education, health, transport, tourism, agriculture, environment, defence, industry, energy and e-government".

3 See M. Hildebrandt, Smart Technologies, cit., p. 7; R. Susskind, Tomorrow's Lawyer. An Introduction to Your Future, 2nd ed., Oxford Un. Press, 2017, p. 11.

4 See R. Susskind, Tomorrow's Lawyer, p. 11.

5 L. Floridi, The 4th Revolution. How the Infosphere Is Reshaping Human Reality, Oxford Un. Press, 2014, p. 25 .

6 As the US Supreme Court affirmed with regard to smartphones (but the reasoning could be extended to other smart technological devices) "These cases require us to decide how the search incident to arrest doctrine applies to modern cell phones, which are now such a pervasive and insistent part of daily life that the proverbial visitor from Mars might conclude they were an important feature of human anatomy" (Riley v. California, 573 U.S. _ (2014)). See G. Lasagni, 'Tackling phone searches in Italy and the United States: Proposals for a technological rethinking of procedural rights and freedoms', New Journal of European Criminal Law, 2018, 383401, p. 391.

7 L. Floridi, The 4th Revolution, cit., Oxford Un. Press, 2014, p. 59; M. Hildebrandt, Smart Technologies, cit., 41; L. Floridi (ed), The Onlife Manifesto. Being Human in a Hyperconnected Era, Springer, 2015. 
is recent in the collective consciousness, the awareness of acting within a legalsphere is much older. It was therefore inevitable the fatal attraction between AI and the law, because both the two drivers tend to pervade - in different ways - the multifarious aspects of the human beings' manifestations. ${ }^{8}$

This cultural attitude toward the potentialities deriving from the interaction between AI and the law is even involving criminal justice, where the theoretical analysis has begun for various years, and relevant studies have been published, ${ }^{9}$ although the number of cases in which AI programs have actually been used as a support tool for adjudication does not amount to more than can be counted on the fingers of one hand.

The European Union and the Council of Europe seem to be aware of the relevant and numerous interactions that may arise from the use of AI systems in the administration of criminal justice. This is confirmed by two well-known documents, the first issued by the European Commission for the Efficiency of Justice (CEPEJ) and the second by the European Parliament. The CEPEJ, on 2018, adopted the first European Ethical Charter on the use of artificial intelligence in judicial systems, with the ambition to provide "a framework of principles that can guide policy makers, legislators and justice professionals when they grapple with the rapid development of AI in national judicial processes". ${ }^{10}$ The LIBE Committee of the European Parliament commissioned a study, published in July 2020, with regard to the effects on fundamental rights deriving from the use of AI systems in the area of law enforcement. ${ }^{11}$

8 G. Ubertis, 'Intelligenza artificiale, giustizia penale, controllo umano significativo', Sistema penale, 2020, 1-15, p. 2.

9 See, among the most recent studies on the topic, S. Quattrocolo, Artificial Intelligence, Computational Modelling and Criminal Proceedings. A Framework for A European Legal Discussion, Springer, 2020 .

10 See CEPEJ European Ethical Charter on the use of artificial intelligence (AI) in judicial systems and their environment, available at the website https://www.coe.int/en/web/cepej/cepejeuropean-ethical-charter-on-the-use-of-artificial-intelligence-ai-in-judicial-systems-andtheir-environment (last access: 20 January 2021).

11 Artificial Intelligence and Law Enforcement - Impact on Fundamental Rights, available at the website https://www.europarl.europa.eu/RegData/etudes/STUD/2020/656295/IPOL STU(2020)656295_EN.pdf (last access: 20 January 2021). 


\subsection{A New Computational Legal Certainty?}

There are various areas of the administration of justice on which the use of AI and ML systems may have some relevant, and possibly positive impact. One of them concerns the capacity of AI to improve the consistency and predictability of legal issues, and especially of potential litigations, two essential features related to the rule of law. This is specifically important for criminal law and criminal justice, where the principle of legality plays a pivotal role, as both the basis and the primary source of justification for the whole system. Legality constitutes not only the raison d'être of criminal law, but also a promise never fully kept, and therefore a cause - in the common academic discourse - of many malpractices of the system. This is mostly true in current times where globalization and the multilevel nature of the sources make legal interpretation (and legal prediction) much more problematic, and are perceived as factors of malfunctioning of criminal law. The problem is felt acutely in civil law countries, where the rhetoric of the Montesquieu's definition of the judge bouche de la loi still exercises a very strong influence.

In the current state of affairs, therefore, AI and ML systems could satisfy, in the end, that relentless quest for certainty and predictability which constitutes the ultimate goal (and the basic philosophical justification) of criminal justice since the post Enlightening reforms. At the same time, they (AI and ML) could also be the primary concern of all those who, directly or indirectly, are affected by the existence of criminal proceedings. The goal of legal certainty could be reached substituting human hermeneutic ambiguity - that is, the inadequacy of humans being able to reach stable interpretation of legal provisions - with computational certainty. In other terms, uncertainty due to human limits in the steady interpretation of the law? may find an end, or at least could be significantly reduced, thanks to self-learning programs capable to elaborate masses of legal data.

The use of AI systems could be extremely helpful in a multilevel integrated legal order, such as that of the European Union, where the multifaceted sources of the law are intertwined in very complex combinations, leaving the human interpreters not rarely uncertain about the legal solution of a matter. Various cases already emphasized such lack of adequate certitude, ${ }^{12}$ due to the expanding of the EU integrated criminal law system, but others could follow, thanks to the increasing complexity of legal provisions. AI could represent an effective

12 One of such problematic case is undoubtedly the well-known Taricco saga, where the direct applicability in criminal matters of the Treaty on the Functioning of the European Union (in particular, of Article 325) was clearly affirmed by the European Court of Justice and, few months later, strongly refused by the Italian Constitutional Court. See, about the numerous analyses published on the case, because of its specific reference to the 
tool to deal with such rising critical features. For example, when the issue of the choice of forum is at stake, in a transnational case, such as when the competence of the EPPO is involved, algorithmic justice could represent a valuable option to objectivise and make clear the matter, that otherwise would remain inevitably left to variable and subjective solutions: ${ }^{13}$ it could significantly help to simplify the criterion of the economical "damage caused or likely to be caused" provided in Article 25 par. 2 and 3 lit. b, which otherwise would risk to undergo to irresolvable disputes between experts in financial economics.

\subsection{Employment of AI Systems in Economic and Financial Criminal Law}

More generally, the strengthening of the hermeneutic side of the law, although reached via methods and technologies unusual for legal practitioners, could be considerably advantageous for lawyers in their counselling activity. They could permit in fact to "calculate" the most probable scenario for their clients, and suggest them the best strategies to be implemented, in order, in primis, to prevent criminal proceedings from arising. Similar advantageous effects could occur - thanks to an appropriate strategy computed in advance - once the criminal proceedings have begun, allowing for the defendant to be exonerated from the charges at the end of the investigations with a dismissal, or to be acquitted at trial (or, at least, to considerably mitigate his criminal responsibility). The ability to take advantage of the AI potentialities as a preventive tool to avoid (or refute) criminal charges seems to be extremely useful with specific regard to economic criminal law. Indeed, companies and commercial enterprises usually suffer severely from the effects of the mere beginning of a criminal investigation, which can compromise the value of their shares and market confidence in their management. The capacity to offer effective defence arguments, based on actuarial predictive models, from the very first moment law enforcement agencies begin their activities, can be a highly effective scheme to reduce the potential harm arising indirectly from the initiation of criminal

problematic features of the legality principle G. Zaccaroni - F. Rossi, 'Settling the dust? An analysis of Taricco II from an EU constitutional and criminal law perspective', available at the website https://europeanlawblog.eu/2018/o4/12/settling-the-dust-an-analysis-of-taricco-iifrom-an-eu-constitutional-and-criminal-law-perspective/ (last access: 20 January 2021).

On the rather vague or too complex provisions concerning the EPPO's competence, see D. Vilas Álvarez, 'The Material Competence of the European Public Prosecutor's Office'; M. Panzavolta, 'Choosing the National Forum in Proceedings Conducted by the EPPO: Who Is to Decide?', both in L. Bachmaier Winter (ed), The European Public Prosecutor's Office: The Challenges Ahead, Springer, 2018, respectively at p. 25 and p. 59. See also D. Brodowski, 'Article 22', in H. H. Herrnfeld - D. Brodowski - C. Burchard, European Public Prosecutor Office, Beck Nomos, 2021, p. 144 and seqq. 
proceedings: for example, they could help to limit the negative impact that a criminal inquiry may have on a listed company on the stock market; or to maintain the confidence of investors, who can be told, on an objective (that is, a computational) basis, that the company has implemented the best possible practices to prevent risk factors linked to the commission of criminal offences.

Actually, there is another reason why economic and financial crimes represent a privileged field to study the impact of the digital revolution in the management of criminal proceedings, especially with regard to fact-finding and evidentiary issues. For a long time, in fact, this kind of crimes - that also includes frauds against EU budget - has been usually committed by falsifying documents, or manipulating other real evidence, with the aim to hide unlawful purposes pursued by the perpetrators to the competent authorities, the shareholders, the creditors, the investors, the media and the public opinion. It is not wrong to affirm that, by tradition, fact-finding in trials concerning crimes against the EU financial interests is prevailingly based on documents: in other words, on written evidence. Oral evidence, on the contrary, plays a complementary role, and it is usually introduced either to explain - under the figure of expert witnesses - what emerges from the papers presented at trial; or to fill the gaps left by the documents, that in their nature constitute circumstantial evidence.

Nowadays, inevitably, in an age of digital economy (and after the advent of the fourth industrial revolution and web 3.0), the "trail" the law enforcement authorities need to follow is constituted by a multiplicity of data, rather than by paper. ${ }^{14}$ It is therefore likely that AI systems could be used to process massive amounts of data related to financial criminal investigations.

\subsection{Managing Prosecutorial Discretion with Algorithms?}

The use of algorithms could furthermore solve various management problems, helping prosecutors in exercising their discretion, as for example in allocating their resources for the investigation and prosecution of cases, or, in systems

See G. Lasagni, Banking Supervision and Criminal Investigation. Comparing the EU and US Experiences, Springer, Berlin, 2019, 1; S. Brayne, 'Big Data Surveillance: The Case of Policing', American Sociological Review, 2017, 980. It may be useful to note that issues concerning the collection and admission of e-evidence are now emerging in many areas of criminal law, due to the digitisation of the economy and all areas of social life. For example, the use of electronic evidence is increasing in the field of international criminal law, where photos, videos, information contained or transmitted through social media are becoming sometimes the main evidence to prove that a crime of international nature has been (or is being) committed. See L. Freeman, 'Digital Evidence and War Crimes Prosecutions: The Impact of Digital Technologies on International Criminal Investigations and Trials', Fordham International Law Journal, Vol. 41, Issue 2, 283. 
where the mandatory prosecution rules (as in Italy), assisting them in elaborating (and enforcing) consistent (and efficient) priority criteria, able to combine principles with practice, and in the end to give the whole system more credibility. ${ }^{15}$

\subsection{A New Mass of Data Derived from Criminal Proceedings}

The current trend is destined to be reinforced thanks to the side-effects of constant recourse to remote criminal justice caused by the Covid-19 epidemic. In every Country, in fact, criminal proceedings are increasingly held online, in whole or, more often, in substantial part, to reduce the risk of infection due to human contact or presence in the same room. Defendants participate with remote online connection; witnesses are examined using digital platforms; judges get together online - instead of getting physically in camera - to discuss the case for the final adjudication. Even investigations where possible are conducted with online instruments, such as Zoom, Meet, Teams another analogous software. ${ }^{16}$ This vast celebration of criminal proceedings online will be the source of a new mass of data that AI systems can use for self-learning and improving the correctness of their predictions. It seems therefore not so much far away the day in which AI systems will be properly tailored to be employed in the administration of criminal justice, with specific reference to various crucial passages of criminal proceedings.

15 Documents setting out the policies and priorities followed by the office have already been published in some Italian Prosecutor's offices. However, the criteria set out are still very vague, and do not allow for an a priori understanding of how they will be applied in practice. See 'Osservanza delle disposizioni relative all'iscrizione della notizia di reato' [Compliance with the provisions on the registration of notices of a crime], available at the website: https://www.questionegiustizia.it/data/doc/1436/la_circolare_della_procura_ di_roma_n_3225_17.pdf (last access: 20 January 2021). On the matter see M. Caianiello, 'Increasing Discretionary Prosecutor's Powers: The Pivotal Role of the Italian Prosecutor in the Pretrial Investigation Phase', Oxford Handbooks Online, 2015, 1-27, p. 10-12.

16 See E. Baker, 'The Crisis that Changed Everything: Reflections of and Reflections on COVID-19', European Journal of Crime, Criminal Law and Criminal Justice, 2020, 311-331, at p. 318. See also J. I. Turner, 'Remote Criminal Justice', Texas Tech Law Review, 2021, 1-76; M. Gialuz - J. Della Torre, D.l. 28 ottobre 2020, n. 137 e processo penale: sulla "giustizia virtuale" servono maggiore cura e consapevolezza, Sistema penale (available online at the website: https://www.sistemapenale.it/it/scheda/gialuz-della-torre-decreto-legge137-2020-processo-penale, last access: 20 January 2021). 
Despite the great potentialities related to the use of AI systems, there is reason to doubt that they can completely satisfy the needs related to the administration of criminal justice, especially when it comes to trial's adjudication. The main reason seems to be that, as it was repeatedly affirmed, algorithms individuate correlations, not causations, while what matters most to adjudicate a criminal case is the latter, not the former.

As it was brilliantly observed, statistical logic is not of much help to attribute criminal responsibility to persons. Statistics, in fact, can tell us how often a certain phenomenon tends to recur. It is not able to tell us why that happens. Furthermore, it cannot tell us with precision anything that concerns the position of a single individual. In other terms, the fact that an individual may be included in a certain class of persons because of certain characteristics, and that there is a certain degree of probability, due to these characteristics, that he has behaved in a certain way, does not tell us anything about what has actually happened. That is, whether that specific individual has actually behaved in a certain way, and on what specific evidence this assertion is supported. Furthermore, it does not explain why, that is on the basis of what combination of causes a fact occurred.

This is why, in the end, Bayesian (or Pascalian) probability calculation actuarial causality, in other terms - does not usually meet the requirements of criminal justice, and is not per se capable of overcoming the presumption of innocence. The only method fitting with how criminal justice is conceived, in fact, seems to be the Baconian (or logical) reasoning, tailored on the facts proven in court through the evidence presented by the parties. The factfinding reached in the judicial reasoning, thanks to the inductive method, the contribution of scientific knowledge and common sense, seems the only way to verify or falsify the specific hypothesis concerning the defendant's criminal responsibility, linking in a chain of inductions and deductions the evidence admitted at trial with the facts - charged by the prosecutor - that need to be proven. ${ }^{17}$ After all, as the old Latin poet Virgil wrote, "felix qui potuit rerum cognoscere causas", 18 since this is where true wisdom lies: "cognitio rei per causas".

17 F. Caprioli, 'L'accertamento della responsabilità penale "oltre ogni ragionevole dubbio", Rivista italiana di diritto e procedura penale, 20o9, p. 51 seqq; F. Caprioli, 'Condanna (Diritto processuale penale)', in Enciclopedia del diritto - Annali (II-1, 2008), Giuffrè, 2008, 101-133, p. 104.

18 Publius Vergilius Maro, 'Georgicae', Liber II, 490 (Publio Virgilio Marone, 'Opere', a cura di Carlo Carena, Utet, 2013, p. 433). 
Under this aspect, the GDPR Regulation 2016/679/EU, as well as the Directive $2016 / 68$ o/UE, according to which a decision based solely on automated processing shall be prohibited, sounds firstly as a description, more than a prescription..$^{19}$ Knowing that there is a certain margin of probability, even a very high one, that a certain event has occurred, does not increase the level of knowledge in relation to that event: we need therefore some further specific evidence, as well as an analysis conducted according to different criteria, in particular following the standards and criteria of reasoning typical of Baconian causality, to close the circle and affirm with rational certainty beyond reasonable doubts - that a certain fact has effectively occurred and that a certain person is criminally responsible for its commission.

It is possible that in the future we could be inclined to see the things differently. The development of AI systems in increasingly refined ways for the administration of justice, and specifically for criminal justice, may lead to change most scholars' perspective, and convince them that AI instruments may improve significantly the quality of judicial decision-making in criminal trials, and in the other stages of punitive criminal justice. There is a field, however, where AI systems may be of great help just now, as they are at the current time, and this is what is addressed as preventive justice.

With this term - as Ashworth e Zender affirm in their seminal work - it is intended the whole set of "measures taken by the state in order to reduce risks to harm". ${ }^{20}$ Such measures are usually not considered as belonging to one single area of the law, being them in part included

- $\quad$ in procedural criminal law and policing (for example pre-trial detention orders; searches and seizures; stop and frisk);

- in civil law (civil preventive orders or actiones in rem);

19 See on the point O. Lynskey, 'Criminal justice profiling and EU data protection law: precarious protection from predictive policing', International Journal of Law in Context, 2019, 162-176, p. 162-163.

20 A. Ashworth - L. Zender, Preventive Justice, Oxford Un. Press, 2014, p. 5. As the authors point out, quoting Walker (N. Walker, Sentencing in a Rational Society, Harmondsworth: Allen Lane, 1972, p. 18), "The more accurate term 'reductivism' has been coined, in recognition of the fact that 'prevention' ought strictly to be confined to the meaning of 'preventing all instances of $\mathrm{x}$ ' the significant reduction of (potentially) harmful behaviour, or the reduction of (potentially) harmful behaviour to a tolerable level". 
- in substantive criminal law (preventive sentencing, but also preventive criminal offences, as inchoate offences or crimes of attempt and conspiracy, substantive offences defined in an inchoate mode)

- $\quad$ in other specific areas of the law (counterterrorism; immigration; football stadium violence; public health law; etc.). ${ }^{21}$

Despite the fact that preventive justice mechanisms or provisions are located in various, sometimes disparate parts of the legal system, they can nonetheless be considered as one definite legal field of public law, no matter if criminal or administrative, with coercive features, as the European Court on Human Rights observed in its jurisprudence. ${ }^{22}$ This is true at least in continental systems where civil law measures and actiones in rem are rather rare. The common characters of the defined matter are, on the one side, the aim to prevent or attenuate to a tolerable level the risk of harmful behaviour ${ }^{23}$ and, on the other, the possibility for the judiciary to issue decisions and orders capable of restricting, in whole or in part, fundamental freedoms, while respecting, however, certain standards of protection of individual rights (and providing for the possibility of judicial review): in particular, personal freedom or freedom of movement, the right to property and the freedom to conduct a business.

The common ground that identifies all such different measures is that they are issued not with the aim to punish (or to react to) an illicit act of the past, but to prevent (or reduce to a bearable level) the risk that a harm will occur in the future. In this sense, the judicial authority competent to adopt these preventive measures, each time it takes action, operates according to a prognostic or predictive judgement, which constitutes the legal (and, before that, political) justification for the restriction of the individual's liberty. There are not therefore - or, at least, there should not be - retributive or punitive purposes in the coercive or restrictive action taken by justices. Prevention or treatment of the individual who is subject to the preventive measure should be the only reasons justifying judicial decisions delivered in this field.

21 A. Ashworth - L. Zender, Preventive Justice, cit., p. 2-5.

22 See ECtHR, Lawless v. Ireland, 1 July 1961, appl. no. 332/57; ECtHR, Guzzardi v. Italy, 6 November 1980, appl. no. 7367/76.; ECtHR, Ciancimino v. Italy, 27 May 1991, appl. no. 12541/86; ECtHR, Raimondo v. Italy, 23 February 1994, appl. no. 12954/87; ECtHR, Villa v. Italy, 20 April 2001, appl. no. 19675/o6; ECtHR, De Tommaso v. Italy, 23 February 2017, appl. no. 43395/og. See M. Pelissero, 'La tutela della libertà personale al di fuori del diritto penale. Misure di prevenzione', Diritto penale Contemporaneo - Rivista Trimestrale, 3/2020, 374-387 (available at the website: https://dpc-rivista-trimestrale.criminaljusticenetwork.eu/pdf/ DPC_Riv_Trim_3_2O2O_Pelissero.pdf, last access: 20 January 2021...). 
This is the case, for example, when the personal liberty of a defendant is restricted during criminal proceedings because there is a risk that he might commit certain serious offences, or tamper with evidence, or fail to appear for trial. But the same approach, albeit with different standards, applies where individual liberty is restricted even before a criminal offence is committed, because a person has engaged in conduct that is considered indicative of a propensity to commit offences: such specific measures are defined by continental scholars as preventive measures ante delictum or praeter delictum. A similar attitude, again, recurs in the judicial decision which, at the time of sentencing (or even subsequently, in certain jurisdictions), applies a detention measure over an individual not for punitive reasons, but to prevent him from committing new serious offences once the sentence has been served. This is the case of the German Sicherungsverwahrung, probably in European jurisdictions the most famous form of preventive detention, that constitutes a type of imprisonment issued for treatment reasons. ${ }^{24}$

\section{5}

\section{Assessing the Individual's Propension to Commit Future Crimes}

This assertion, that AI system may fit more for preventive justice than for punitive criminal justice, can be open to some prima facie well-grounded criticism. Actually, AI systems present the same limitations, no matter if they need to be applied to retributive justice or in the multifaceted areas of preventive justice. Fact-finding constitutes a necessary element of both kinds of justice, retributive-punitive, on the one hand, and preventive, on the other. In both the fields, in fact, the human event at the basis of the judicial decision is not scientifically demonstrable to the full. Judges therefore rely on/need to use inductive and deductive reasoning mechanisms based on scientific rules and common sense in both cases. ${ }^{25}$

24 It is well-known that many European jurisdictions, inspired to the so-called "double track system", provide for two forms of imprisonment, that give origin to divergent forms of detention (detention as punishment and detention as treatment). See K. Drenkhahn - C. Morgenstern, 'Preventive Detention in Germany and Europe', in A. R. Felthous - H. Saß (eds.), The Wiley International Handbook on Psychopathic Disorders and the Law, 2nd Edition, 87106. See also, with an analysis conducted before the case Ilnseher v. Germany was issued by the European Court on Human Rights (ECtHR, Grand Chamber, Ilnseher v. Germany, 4 December 2018, Appl. nos. 10211/12 and 27505/14), J. Kinzig, 'The ECHR and the German System of Preventive Detention: An Overview of the Current Legal Situation in Germany', in M. Caianiello - M. L. Corrado, Preventive Detention. New Paradigms in Criminal Justice, North Carolina University Press., 2013, p. 71-95.

25 This is what observes F. Caprioli, 'Pericolosità sociale e processo penale', in M. Pavarini - L. Stortoni (eds.), Pericolosità e giustizia penale, BUP, 2013, 21-43, p. 23-26. 
However, in practice, things are quite different, and actuarial mechanisms may play a role of much greater impact on preventive rather than on retributive justice. This is due to the fact that, on the one hand, the harmful event justifying restrictive judicial intervention is, in ex post facto punitive justice, precisely identified (and it must be ascertained that it has occurred with almost absolute certainty); on the other hand, future dangerous (or illicit) behaviours are simply evoked in an indeterminate manner, sometimes to the point of remaining entirely generic, in preventive ex ante facto justice. This is even more true for what concerns the location of the offence in space and in time. While, in fact, in retributive justice ubi, quomodo and quando of the criminal event constitutes crucial passages for the cases of both the prosecutor, that bears the burden to prove each of the characters of the fact with precision, and the defence, that needs to raise a reasonable doubt in at least one of the three aspects, the same does not happen with regard to preventive justice. Here, on the contrary, the three specific features in question rarely, if ever, constitute a necessary element of the preventive legal provision. Usually in fact the prosecutor is required to prove that there is a certain level of risk of a certain kind of harmful behaviour, rather generally depicted, while he is exempted from proving when, how and where such behaviour should occur.

In other words, in preventive justice the fact tends to fade away. It follows that the principal, and, in practice, almost exclusive object of the preventive decision is the individual, on whom a prognosis of dangerousness is formulated. Here is where AI systems come into play, and where they can bring a real and consistent improvement. For a long time now, the assessment of an individual's personality, in order to decide whether to adopt a preventive judicial decision, has been strongly influenced by subjective factors. Judges often end up deciding on the basis of personal experience, of their impressions, influenced not infrequently on emotions aroused by the hearing in which they participated (and on prejudices which, even unconsciously, influence them). In addition, evidence and data at their disposition are rather poor: in practice, they are limited to criminal records, information about ongoing criminal proceedings involving the person whose dangerousness has to be assessed, police reports (or, in the luckiest cases, social services reports) describing certainly not with the mastery of Dickens or Zola - the life habits, friendships and acquaintances of the person to be judged, his economic condition and family status. As can easily be seen, this is incomparably less than an AI system can compute, drawing on a increasingly large amount of data, which is constantly being updated, thanks to the digital trail left by the person constantly living onlife. 


\section{Scepticism toward Traditional Sciences and Impact of Human Emotions}

It should be added that, precisely in relation to evaluating the personality of the individual and his propensity to commit crimes, traditional science seems to show its most significant limitations. Psychology and psychiatry, as well as social studies on the criminal personality of the individual, have produced unsatisfactory results in terms of their reliability and precision in practice. Sometimes scepticism toward this kind of evidence is even recognised in the law. For example, the Italian Code of Criminal Procedure, ${ }^{26}$ at Article 220 par. 2 , provides that

"expert evidence shall not be admitted to determine whether the accused is a habitual or professional offender or he has a tendency to commit offences or to establish the character or personality if the accused and, in general, his psychic qualities independent of pathological causes". ${ }^{27}$

Of course, lack of trust toward traditional sciences dealing with the personality of the individuals is not the only reason for this sort of provisions. The legislator usually aims, first of all, to exclude from the trial evidence that could alter the impartiality of the court, thus undermining the factfinding's reliability reasoning. ${ }^{28}$ However, it is undeniable that the rule of exclusion is also due to the shared opinion that at trial experts' statements on individual personality in many cases lack of sufficient probative value. Under this aspect, one should not underestimate how problematic may be recruiting suitably trained experts in criminal

26 It is worth clarifying that in this contribution the references to the Italian system are made merely as an example, and not to conduct an in-depth analysis. The thesis that is sustained, starting from the research of Ashworth and Zender, is that the general characteristics of preventive justice recur in a similar way in most European systems. However, from time to time, when it is necessary for the sake of clarity to consider one particular feature of preventive justice, I will refer to specific legal provisions taken from the Italian system, with which I am more familiar.

27 M. Gialuz, L. Luparia, F. Scarpa (eds.), The Italian Code of Criminal Procedure, Wolters Kluwer - Cedam, 2014, p. 193-194.

28 The prohibition under consideration, in fact, aims also to prevent factfinding from being confused (and improperly biased) with the judgement of the defendant's character. This is why, in the Italian system, a proper assessment of the character of the accused is reached at a later stage, when the conviction has become final, at the sentencing stage (or even later, during the serving of the sentence). See F. Caprioli, 'Processo penale e commisurazione della pena', in M. Pavarini (ed), Silète poenologi in munere alieno! Teoria della pena e scienza penalistica, Monduzzi, 2006, 135-153. 
proceedings, who are able to present their knowledge in a way that is comprehensible to the lawyers - and first of all to the judges - who need to issue a very practical decision on whether convicting or acquitting the defendant. After all, the increasing recurrence to neuroscience in criminal proceedings, as well as in other fields related to the administration of justice, is also due to this sense of dissatisfaction with the use of more traditional studies of the human psyche, when a concrete judgement has to be made on an individual's propensity to commit crimes in the future. ${ }^{29}$

Finally, it should not be overlooked that, as it has been shown in some studies, the emotional state of the judge (and the jurors) can have a very significant influence on the decision to be taken. In a well-known research carried out a few years ago, it was found, under this regard, that tiredness tended to influence judges' decisions, with significant practical consequences. In particular, judges seemed inclined to keep a milder attitude in sentencing after breaks from work, such as coffee breaks, and a harsher attitude when pauses are still far away in the schedule. ${ }^{30}$

If we want to briefly summarise the reasons for dissatisfaction with the methods and results that traditionally characterise human judgement of an individual's tendency to commit crime, we can therefore conclude that they are based on the following recurring factors: poor information; lack of a sufficiently solid scientific basis (combined with troubles in translating scientific knowledge into criminal trials through traditional methods such as testimony); excessive influence of emotional factors in the decision. ${ }^{31}$

As it has already been said, these are all critical aspects that can all be better and more efficiently managed thanks to the use of AI systems. This is due to two different reasons. On the one hand, the mass of data that can be computed by AI systems is immeasurably greater than that which even the best judge can process. On the other hand, and above all, the traditional type of causal reasoning (Baconian, as defined above), in this field, seems able to offer rather inadequate results, in comparison with which, instead, algorithmic actuarial

29 See M. Caianiello, 'Criminal Process faced with the Challenges of Scientific and Technological Development', European Journal of Crime, Criminal Law and Criminal Justice, 2019, 265-289, p. 278 (and the sources mentioned therein).

$30 \quad$ See D. Eagleman, The Brain - The Story of You, Canongate Books, 2015, p. 266.

31 Of course, our intention is not to claim that these critical factors occur in every case, but that they tend to recur with a certain frequency, and are as such recognised in numerous studies carried out in this area. 
calculation appears capable - prima facie ${ }^{32}$ - to provide more useful answers on a practical level.

\section{Dangers Related to the Use of AI in Preventive Justice. The Risk of an Acritical Submission to the Algorithm Prediction}

If the employment of AI and ML systems may improve effectively the administration of the multiple forms in which preventive justice takes places, it also implies new risks and potential flaws that should not be underestimated. The first concerns the general tendency of human beings to uncritically implement on the algorithm's outcome. The perception of knowledge's disproportion between what the ML knows (and is able to elaborate in extreme shortest terms) in comparison with human beings is such that the latter will easily be inclined to take up what the machine suggests to them without too much trouble. Studies have shown that the risk of an uncritical reception of the AI systems' outcome is far from being remote, and may affect the decision no matter if the latter is supposed to be taken by a single person or a body of people (as for example such as a board of managers of a company). ${ }^{33}$ This risk seems especially high with regard to preventive justice, whose decisions are always based on dangers' predictions. Prediction, indeed, is what AI systems and ML are designed to do, and they can do it extremely well and very quickly. Judges and lawyers are indeed well aware of the typical limits affecting such decisions when adopted without the help of AI tools (poor information, lack of solid scientific bases - at least in a relevant number of cases -, influence of emotional factors). This is why they may be inclined to heavily rely on algorithmic predictions, that may appear at first sight sounder and more accurate. The immense sets of data, increasingly developing thanks to the use of digital devices, the capacity to elaborate the whole jurisprudence relevant for the case, the absence of emotional factors influencing decision-making are elements which can improve the quality and

32 Of course, the use of AI systems can also be open to some significant criticism, as it is well-known, and can lead to relevant errors of approach (some of which will be discussed below). One of the best known, and very well highlighted by numerous studies in this field, concerns the quality of the data fed into the AI system, which can be biased. In this case, the AI does nothing more than amplify the bias that affects the data fed into the system at the beginning of the process, giving the final result the semblance of objectivity that, on the contrary, is lacking due to the initial quality of the processed data. Cfr. G. Contissa - G. Lasagni, 'When it is (also) Algorithms and AI that decide on Criminal Matters, cit., p. 285-288.

33 L. Enriques, 'Responsabilità degli amministratori e ruolo degli algoritmi: brevi annotazioni sul senno di poi 4.o', in U. Ruffolo (ed), Intelligenza Artificiale. Il diritto, i diritti, l'etica, Giuffrè, 2020, 295-299. 
efficiency of the system so much that judges may end up not placing too much emphasis on the limits and flaws of actuarial justice. In particular, they could be inclined to underestimate one of the problems affecting ML and AI predictions, like emphasized bias effects resulting from elaborated data, ${ }^{34}$ because, after all, biases and prejudices have undermined since long-time this field of justice. In other terms, critical factors affecting AI models - especially if related to the selection of the set of data computed by the machine - per se could not appear serious enough to prevent courts from having a certain sort of acritical attitude when dealing with actuarial ML-based prognoses. The caution requested in the use of these predictive models in the first applications of case law ${ }^{35}$ therefore risks constituting little more than a formula of style, resulting in a few words of circumstance in the reasoning of the judicial decision (who may uncensored rely heavily on the algorithm outcome).

Furthermore, in this area of justice there is no possibility that the facts will disprove the prediction on which the judge's decision is based. The measure that the judge adopts, in fact, prevents the criminal fact that is feared from occurring. This, however, considered from a different perspective, means that one can never know whether the offence did not occur thanks to the preventive measure or because the prediction was wrong (and the person involved would never have committed the offence). ${ }^{36}$ This state of affairs, that is inevitable in the legal field under consideration, ends up constituting a further factor in favour of an uncritical trust attitude toward algorithmic predictive justice. After all, apart from the absence of many contaminating factors that condition human beings, the reasoning underlying the judicial decision cannot be

34 G. Contissa - G. Lasagni, 'When it is (also) Algorithms, cit., p. 293. See also A. G. Ferguson, 'Policing predictive policing', in Washington University Law Review, 2017, 1109-1189 p. 1146; S. Brayne, 'Big Data Durveillance: The Case of Policing', in American Sociological Review, 2017, 977-1008, p. 998; M. Degelind - B. Berendt, 'What is wrong about Robocop ad consultants? A technology-centric critique of predicting policing', in AI \& Soc., 2018, 347-356, p. 353; S. Quattrocolo, Artificial Intelligence, Computational Modelling and Criminal Proceedings, cit., p. 67 .

35 This is what happened in the well-known case of Loomis v. Wisconsin, July 13, 2016 (State $v$. Loomis, 881 N.W.2d 749 - Wis. 2016), where the Court observed that due process safeguards imply that algorithmic methods are used with caution. See 'Criminal Process faced with the Challenges of Scientific and Technological Development', cit., p. 282. See also K. Freeman, 'Algorithmic Injustice: How the Wisconsin Supreme Court Failed to Protect Due Process Rights in State v. Loomis', in N.C. J.L. \& TECH., 2016, v. 18, 75-106. For further judicial cases adjudicated using AI algorithms see G. Contissa - G. Lasagni, 'When it is (also) Algorithms, cit., p. $287-288$.

36 T. Padovani, 'Fatto e pericolosità', in M. Pavarini - L. Stortoni (eds.), Pericolosità e giustizia penale, cit., 117-137, p. 131. 
disproved a posteriori. Things are, and for a quite a time to come will continue to be different in the field of punitive justice, which is all about establishing if, why and how the crime has already taken place, and who exactly committed it. Here, the inability of the AI system to reason by causal inferences seems to constitute a critical factor of greater importance. In fact, it leaves a margin of unresolved questions which may have a decisive weight, from the judge's perspective, to detach himself from the elaboration of the algorithm.

\section{The Need to Rethink Preventive Justice in the Light of the New Potentialities Offered by the Use of AI Systems}

The elements exposed up to now, and the trends that at the current time are emerging, predicting a high potentiality for AI to interact (and condition) the administration of preventive justice, make it appropriate to rethink and reshape this field of public law. Preventive justice is often flawed by some common problem that Ashworth e Zender very clearly outlined in their research. ${ }^{37}$ The most important shortcoming regards the lack of adequate precision in the legal provisions. Vagueness in legislation may indeed affect the definition of the crime or the illicit fact to be prevented, the dangerousness of the person suspected, and the standard of proof regarding the danger.

\subsection{The Definition of the Crime to be Prevented}

With regard to the definition of the crime or the fact to be prevented, the law rarely is adequately precise, usually being limited to require the suspicion that a person have committed (or may commit) an offence (or an illicit act), without any further specific indication. For example, in the Italian system, the code of criminal procedure does not identify in stringent terms the future crimes that there is reason to believe the defendant may commit, when the judge issues a pre-trial detention order. Despite the numerous reforms issued by the Parliament in over 30 years, all aimed to reduce the judicial propensity to issue pre-trial detention measures, the normative provisions are still quite ineffective under this regard. The law in fact only individuates general categories of crime, such as the risk of committing "serious crimes with the use of weapons or other violent tool against persons", or crimes against the "constitutional system", or crimes "of the same type to the one under prosecution, as long as it is sentenced with at least a maximum term of 5 years of imprisonment": dealing

37 A. Ashworth - L. Zender, Preventive Justice, cit., p. 25 o and seqq. 
with such provisions, there is ample leeway for the judge to define the risk specifically attributed to the defendant.

The same holds true for preventive detention, or for preventive measures limiting the individual's freedom ante (or praeter) delictum. With regard to the former, for example, the Italian Code of Penal Law is extremely undetermined, providing only that it can be issued when the defendant is "socially dangerous" (Article 202 par. 1), referring, with that definition, to a person, who has committed a crime, "when it is probable that he will commit further crimes" (Article 203, par. 1). The same happens for the latter, where the legislator usually leaves the judge a broad discretion in deciding whether to take preventive action: for example, in the Italian system, the law simply requires that the person concerned "may be considered dangerous", meaning that it is probable that he or she will commit crimes. ${ }^{38}$

\subsection{The Criteria for the Assessment of Individual Dangerousness}

With regard to the assessment concerning the individual's dangerousness, legal provisions usually do not go much further than asking the judge to focus on the behaviour of the defendant, his concrete actions and criminal record. In other passages, legislation requires the judge to consider, in addition, the reasons why the defendant committed a crime, or the defendant's individual, family and social living conditions. Sometimes the law is extremely vague, and formulated in terms worthy of a nineteenth-century serial novel, referring, for example, with regard to the Italian system of preventive non-penal measures, to persons "habitually engaged in criminal activities", or persons "who habitually live, even partly, on the proceeds of criminal activities". 39

\subsection{Standard of Proof}

Lastly, the norms are ineffective also for what matters the legal standard of proof necessary to justify the issuing of a preventive measure, where the law

38 For example, with regard to the most serious measures applicable in the Italian system, the Legislative Decree no. 159, September 6th, 2011 (Code of anti-mafia laws and prevention measures) requires, on the one hand, the mere suspect that the person concerned is committing or has committed a serious crime (such as being part of a criminal organisation, or facts committed with purposes of terrorism) and, on the other, that this person is dangerous, in the definition referred above that it is probable he will commit other crimes. See F. Menditto, 'Presente e futuro delle misure di prevenzione (personali e patrimoniali): da misure di polizia a prevenzione della criminalità da profitto', in La giustizia penale preventiva, Giuffrè, 2016, 145-191, p. 167-168.

39 Article 1, Legislative Decree no. 159, September 6th, 2011. 
may sometimes evoke the occurrence of a "real risk" of committing crimes, or, in other provisions, the mere risk, and, in further hypotheses, even the simple possibility that a crime (or a dangerous behaviour) may be realised.

\subsection{Suitable Reforms}

These characters of preventive justice - which all highlight the problem of the regulatory provisions' lack of precision - tend to afflict most national systems, of course with different nuances and grades of departure from a strict respect for the rule of law and the need for predictability of judicial decisions. In the current status quo, it is easy to foresee (there is no need for any algorithm about it!) that AI system will acquire a great deal of influence in a relatively short time in this field, because they be easily be perceived as programmed to perform what judges do, with better and more effective means.

Faced with this likely looming scenario, one can have three attitudes. The first consist in an acritical rejection of what the new algorithmic tools under consideration may offer. The second, on the contrary, in an acritical acceptance of the ongoing changes. The third, eventually, is to take advantage of such great transformation that is about to occur, in order to introduce relevant modifications, long conceived and proposed for preventive justice although rarely, if ever implemented. In this respect, again, a stricter and more effective compliance with the parameters suggested by Ashworth and Zender seems within reach (we refer to that research for a full exposition of the proposals contained therein). Among numerous recommendations, worth mentioning seems in particular the "presumption of harmlessness" that every individual should enjoy, which is a specific consequence of the more general presumption of innocence typical of criminal law. By virtue of this principle, any individual cannot be presumed dangerous except in serious circumstances, usually recurring when he has committed a crime defined by law - in clear and detailed terms - as serious. Therefore, in presence of simple suspects that the person concerned has committed a serious crime the presumption stands, and needs to be reversed entirely by the Government which bears the burden of proof. Another feature worth of consideration regards the assessment of the individual's dangerousness. As the oft-quoted authors observe

"Any judgment of dangerousness in this context must be approached with strong caution. It should be a judgment of this person as an individual, not simply as a member of a group with certain characteristics and with an overall probability rating. The state should bear the burden of proving that the person presents a significant risk of serious harm to others and the required level of risk should vary according to the seriousness 
of the predicted harm, [as well as, in my opinion its proximity in time]. Decision-makers should bear in mind the contestability of judgments of dangerousness and the scope for interpretation that they leave and individuals should have rights of challenge and appeal". ${ }^{40}$

One of the reasons why such praiseworthy suggestions have rarely been implemented concerns the fact that, by making the verification of the dangerousness of the individual excessively rigorous, preventive intervention would end up being adopted only in a too limited number of cases. Therefore, the system would not satisfy the need for security that the State undertakes to guarantee, in the social contract with its citizens. In other words, under this perspective, the government and the judiciary should be left a certain amount of leeway, for the sake of prevention effectiveness. Without some significant margin of discretion, in fact, it would never be possible to take appropriate and effective action to prevent the commission of crimes or other offensive or dangerous acts.

There is a further reason that has often legitimised lower standards of individual prerogatives' protection in preventive justice than in punitive justice. It is due to the practical function that preventive justice measures must fulfil, as a sort of plan B, designed to target persons who have escaped conviction in the traditional criminal process. In essence, cases where the defendant cannot be convicted because a certain margin of uncertainty remains (the well-known reasonable doubt), can be adequately dealt with by means of preventive justice, which, in this way, ends up acting as an ex post facto remedy for a failed conviction (in the pre-Enlightening systems, these were the models imprinted to the so-called mala fama - bad reputation - and the semiplena probatio half-full evidence) ${ }^{41}$

The improved potentialities related to the predictions calculated by AI systems make these limits and flaws in the conception of preventive justice no longer justifiable. In other words, it is a matter of applying to the new context an adequate proportionality check: if the means at the disposal of law enforcement become more powerful and invasive, the margin of manoeuvre granted to it must be proportionally reduced. Therefore, if the AI system can access an enormous quantity of data to calculate the dangerousness of an individual (unlike what happens with the judge), it is reasonable to ask a much higher level of precision (a burden that the AI system can fulfil). Preventive justice

$40 \quad$ A. Ashworth - L. Zender, Preventive Justice, cit., p. 169.

41 M. V. Vallerani, 'Modelli diverità. Le prove nei processi inquisitori', in J. Chifilaeau, C,. Gauvard (eds.), L'enquête au Moyen Age, Ecole Française de Rome, Roma, 2008, p. 123-142. 
must be subject to guarantees and limits appropriate to the aims pursued, and to the respect of the dignity of the individual (first of all, his right to be considered, in a concrete and effective way, as harmless). In other terms, just because actuarial justice seems to be - if properly developed - such a strong tool for preventive justice, the legal standards usually provided in this area need to be properly rethought and consistently upgraded, so that the contours of the preventive state may respect the rights of the individual in full.

At the same time, AI models need to be properly tailored for the necessities of this particular area of justice, where they are supposed to be used. ${ }^{42}$ Therefore, programs developed for different objectives - for example for preventive policing activities - should be excluded as such from the use within the preventive judicial proceedings, unless it is proven that they fit with the specific purposes pursued therein. Just to make a very simplified example, if one AI system is conceived, in case of uncertainty, to opt for false positives instead of false negatives, as is the case for HART, ${ }^{43}$ it should not be admitted as legitimate tool within the judicial proceedings. What is appropriate for preventive policing, in fact, is not suitable in most cases for preventive justice (and even less for criminal proceedings stricto sensu). Of course, the control over the way in which the AI system intended to be used in the judicial proceedings has been programmed should extend to many other factors (which it is not possible to examine in detail in this contribution), such as the type and the quality of the set of data the AI was trained. ${ }^{44}$

Eventually, there is a last element, perhaps the most delicate one, on which it is urgent to develop an adequate reflection, so as not to be caught unprepared and not to suffer passively the effects of the use of AI systems. The problem can be summarised in a single question: what is it necessary - or even preferable - that remains strictly within the competence of the human beings, and therefore can never be entrusted to the machine? This question is linked to what we consider essential for the progress of people, both as individuals and above all as components of a social context. Justice is, subject to no matter how complex regulatory provisions and difficult rules may be, a social manifestation through which people - particularly the social consortia to which they

42 It is realistically more difficult to monitor the performance of ML (data-driven algorithms) over time since they learn time after time from the data they are given. For these cases it seems useful to refer to an auditing system as Contissa and Lasagni propose (G. Contissa - G. Lasagni, 'When it is (also) Algorithms and AI that decide on Criminal Matters, cit., p. 301. G. Contissa - G. Lasagni, 'When it is (also) Algorithms and AI that decide on Criminal Matters, cit., p. 285 .

44 Furthermore, effective remedy should always be ensured, as the law requires. See under this aspect G. Contissa - G. Lasagni, 'When it is (also) Algorithms, cit., p. 288-29o. 
belong - tend to improve themselves. Put differently, one might affirm that in taking judicial decisions, even if it is not always possible to ensure that justice is done in any given case, a society as a whole progressively learns how to become fairer. In this perspective even the single judicial mistake may end up being useful, because, over time, through the reflection of scholars and social bodies, it constitutes, even in spite of itself, a tool for improvement. In this sense, it becomes extremely important to identify what constitutes the core business of the matter, which must be reserved in the domain and accountability of human beings, so that this self-learning function typical of our species - doing justice - is not lost with time.

\section{$9 \quad$ Conclusions}

Many of the events that have occurred in recent years (and sometimes months, if we think to the pandemic tragedy that affects our current lives) have been perceived by lawyers - and not only by them - as passing phenomena, such as not to change the traditional way of administering justice as it has developed since the Second World War. Many of us are just waiting to get back to normality, in other terms, where this concept, normality, is intended as the way in which we were used to live our lives and do our business the same way we did earlier.

On the contrary, it is realistic that some factors that have emerged as relevant in these critical times are capable of causing a stable change (albeit unknown in terms of effects) in several key sectors of criminal justice. One of the areas that seems to be most sensitive to the new potentialities made available by AI systems' development is preventive justice: although this sector has been necessary since the original theoretical conceptions of the modern state, ${ }^{45}$ it

45 For an historical reconstruction of the political and philosophical foundations of preventive justice, see A. Ashworth - L. Zender, Preventive Justice, cit., p. 27 and seqq. Cesare Beccaria too, in his work on Crimes and Punishments, recognized the importance of the prevention of crimes. Actually, Beccaria was not in favour of preventive measures, basing his whole work on the foundation of the punitive-retributive justice. Nonetheless, he could not deny that prevention of crimes constitutes an essential task of any government. In the final part of his book, he actually admitted that "It is better to prevent crimes than to punish them. This is the principal goal of all good legislation". However, the only means to implement an effective policy on crimes prevention remained, for the Milanese philosopher, on the quality of legislation: "Do you want to prevent crimes? Then make sure that the laws are clear and simple and that the whole strength of the nation is concentrated on defending them" (C. Beccaria, On Crimes and Punishments and Other Writings, Cambridge Un. Press, 1995, p. 103-104). 
appears still rather unsatisfactory today in terms of results and standards of protecting individual rights. It would be a good idea to seize the opportunity presented by the changes taking place in the current times, trying to introduce those long overdue safeguards, while also encouraging a targeted use of AI and ML systems to give the sector more predictability and consistency.

If legislators will be able to do this, there is a serious chance that they will succeed in improving a system which, for a long time, has remained underdeveloped on the level of theoretical reflection, although increasingly used, on the practical level. Otherwise, there is a risk that this area of public law will be left to the undisputed dominance of AI and ML models. This is an undesirable scenario, because it could cause two major damages to a legal sector that seems already critical under several respects. Firstly, it would consolidate the inadequate level of protection of fundamental rights; secondly, it would risk in practice, in the long term, to oust the human factor from the decision on the dangerousness of the individual, thus depriving this field of justice of the humanism that is crucial for the development of collective consciousness in complex social organisations.

The ultimate challenge, in the final analysis, is to ensure that the use of machines helps to improve our humanism, and does not eliminate it.

\title{
Acknowledgements
}

I am indebted to Isadora Neroni Rezende for her helpful comments and remarks on the first drafts of this editorial.

\author{
Michele Caianiello \\ Professor of Criminal Procedure, Department of Legal Studies, University of \\ Bologna, Bologna, Italy \\ michele.caianiello@unibo.it
}

